\title{
PARTICIPACIÓN DE LA SOCIEDAD CIVIL EN EL DERECHO DE ACCESO A LA INFORMACIÓN PÚBLICA ${ }^{1}$
}

\author{
María del Carmen Morales Tostado ${ }^{2}$ \\ María de los Ángeles Monterde Valenzuela ${ }^{3}$ \\ Reyna Guadalupe Morales Tostado ${ }^{4}$
}

SUMARIO: I. Introducción.II Antecedentes y evolución de la estructura legal de la transparencia y el derecho de acceso a la información pública. III. Participación de la sociedad civil. IV.Conclusiones

\section{RESUMEN}

En la presente investigación, se revisa el marco legal de la transparencia y el derecho de acceso a la información pública, iniciado desde los antecedentes del derecho humano a la información desde una perspectiva internacional. Así mismo, la evolución que ha tenido la estructura legal de la transparencia y derecho a la información pública, brinda seguridad jurídica a los ciudadanos para que puedan acceder a la información que les interese de las gestiones y desempeño del gobierno. También, se revisa el proceso de construcción de ciudadanía, donde el derecho de acceso a la información cobra vital importancia y se investiga el número de solicitudes que han realizado al Instituto Nacional de transparencia, acceso a la información y protección de datos personales (INAI) de 2003 a 2019.

Palabras clave: Derecho de acceso a la información, transparencia gubernamental y sociedad civil.

\footnotetext{
${ }^{1}$ Los resultados y propuestas de esta investigación se presentaron en en el "2020 Juried Virtual Conference" Western Social Science Association 62nd Annual Conference June 10 through September 30, 2020

2 Docente Investigadora de Universidad de Sonora. México. Correo electrónico: carmen.morales@unison.mx.

${ }^{3}$ Docente Investigadora Universidad Estatal de Sonora. México. Correo electrónico: angelesmonter50@hotmail.com

${ }^{4}$ Docente de asignatura. Universidad de Sonora. México. Correo electrónico: reyna.morales@unison.mx
} 


\title{
Participación de la sociedad civil en el derecho de acceso a la información pública
}

Volumen 12, Número 22 ene-jun 2020

Morales Tostado \& Monterde Valenzuela

\section{PARTICIPATION OF CIVIL SOCIETY IN THE RIGHT OF ACCESS TO PUBLIC INFORMATION}

\author{
María del Carmen Morales Tostado \\ María de los Ángeles Monterde Valenzuela \\ Reyna Guadalupe Morales Tostado
}

SUMMARY: I. Introduction. II Background and evolution of the legal structure of transparency and the right of access to public information. III. Participation of civil society. IV. Conclusions

ABSTRACT
In the present investigation, the legal framework of transparency and the right of access to public information is reviewed, based on the background of the human right to information from an international perspective, as well as, the evolution that the legal structure of transparency and the right to public information. Also, the citizenship construction process is reviewed, where the right of access to information becomes very important and the number of requests made to the National Institute for transparency, access to information and protection of personal data (INAI) is investigated from 2003 to 2019.

Keywords: Right of access to information, government transparency and civil society

\section{INTRODUCCIÓN}

Para abordar la temática del derecho de acceso a la información, primero se analiza desde la perspectiva de la percepción ciudadana, luego pasamos al análisis del entorno de los sujetos obligados. En relación a la perspectiva del ciudadano, se critica duramente la función del gobierno, se habla de corrupción, de proteccionismo de grupos políticos, de beneficiar a los accionistas de empresas en donde los servidores públicos otorgan 
concesiones, entre otros. Todo esto propicia que no exista confianza en las entidades gubernamentales.

También, se percibe que sujetos obligados a transparentar la información sobre su gestión, así como, a dar respuesta a las solicitudes de información que reciben de los ciudadanos enfrentan diversos problemas para cumplir con las disposiciones que establece en la Ley de Transparencia.

Dentro de ellos, se pueden señalar que en algunos de los sujetos obligados: la documentación no se somete a una clasificación, organización y conservación adecuada, luego la información que se publica en sus páginas electrónicas no está actualizada, o es difícil de interpretar. Otro problema, es el relacionado a las personas que integran el recurso humano de los sujetos obligados, que presentan resistencia al cambio, y el cumplir con las obligaciones de transparencia y de acceso a la información significa una mayor carga de trabajo, ya que se tiene que organizar, salvaguardar y capturar la información para que se pueda poner a la vista de los ciudadanos.

Considerando lo anterior, es una prioridad la transformación de las instituciones públicas, para estar en condiciones de cumplir con la Ley de Transparencia, en virtud de que enfrenta obstáculos por inercias en su desempeño. Por eso es necesario destacar lo expresado por Vergara quien establece lo siguiente:

La transparencia no es fácil, no es una condición natural de las organizaciones gubernamentales; para decirlo con un clásico de las organizaciones, Giandomenico Majone las burocracias no nacen transparentes, mucho menos en tradiciones gubernamentales como la mexicana. Por eso, la transparencia debe elaborarse, construirse, implementarse cuidadosamente, con una visión de largo plazo que asuma al mismo tiempo diferentes objetivos: legales, reglamentarios, políticos, organizacionales, educativos, culturales, dentro y fuera de las instituciones del Estado. ${ }^{5}$

\footnotetext{
${ }^{5}$ Vergara Rodolfo, La Transparencia como problema. Serie de Cuadernos de transparencia número 5. México, 5ta. ed., IFAI. México,2008, p.5
} 


\section{Participación de la sociedad civil en el derecho de acceso a la información pública}

Volumen 12, Número 22 ene-jun 2020

Morales Tostado \& Monterde Valenzuela

Es claro el mensaje de Vergara, en relación a que es necesario que las organizaciones burocráticas se transformen en organizaciones transparentes, mientras no haya esa transformación seguirá el serio problema de la opacidad. Para coadyuvar a estos cambios trascendentales, se debe diseñar e implementar estrategias que lleven a una transformación, donde se promueva una cultura, en la que los individuos asuman plena y conscientemente su responsabilidad en el contexto donde se encuentren, de la misma forma la institución se obliga a participar en procesos de mejora y de evaluación.

Es de suma importancia, analizar la participación de la sociedad civil tanto en la exigencia de un gobierno abierto y transparente, así como en el ejercicio del derecho de acceso a la información pública, ya que le permite conocer cualquier aspecto sobre el desempeño del gobierno y de las organizaciones que reciben recursos públicos. Aunado a ello, la Ley de Transparencia, intenta permear en la cultura de los ciudadanos, desde dos contextos totalmente diferentes: El primero es relacionado a la cultura de los servidores públicos para que sean honestos e informen sobre su quehacer considerando la información que están obligados a ofrecer a quien lo solicite sin restricción ni pretextos. El segundo se refiere a que es necesario que los ciudadanos identifiquen y conozcan el derecho otorgado por la Constitución y la Ley de Transparencia, que les permite vigilar a los servidores públicos, las obras que estos realizan y al mismo tiempo solicitar la información en poder del gobierno.

Si los ciudadanos se interesan y participan en la identificación y solución de los problemas sociales, en la formulación de políticas públicas, diseño de estrategias y vigilancia y evaluación del desempeño de los servidores públicos, México transitará a mejores condiciones de vida para sus habitantes y en un futuro se reducirán las desigualdades entre la población. 
Otro factor primordial es la utilización de las tecnologías de información y comunicación, en ese tenor es necesario compartir lo planteado por Quintanilla y Gil que dicen:

En la última década, las tecnologías de la información han sido, en mayor o menor medida, instrumentos de reforma administrativa que pueden ayudar a los gobiernos a generar mecanismos para ser más eficientes, transparentes y participativos. ${ }^{6}$

Por ello, se considera importante señalar lo que comparte el Instituto Nacional de Estadística y Geografía (INEGI), en su comunicado 103/20 de fecha 17 de febrero de 2020, donde según los datos de la Encuesta Nacional sobre Disponibilidad y Uso de Tecnologías de la Información en los Hogares (ENDUTIH), en México hay 80.6 millones de usuarios de Internet, que representan el $70.1 \%$ de la población de seis años o más.

Así mismo, se estima que son 20.1 millones el número de hogares que disponen de Internet (56.4\%), ya sea mediante una conexión fija o móvil, lo que significa un incremento de 3.5 puntos porcentuales con respecto a 2018. isçp. De los 80.6 millones de usuarios de Internet de seis años o más, $51.6 \%$ son mujeres y $48.4 \%$ son hombres. isepentre 2017 y 2019 , los usuarios en la zona urbana pasaron de $71.2 \%$ a $76.6 \%$, mientras que en la zona rural el incremento fue de $39.2 \%$ a $47.7 \%$ de usuarios de 6 años o más. También se conoce, que los tres principales medios para la conexión de usuarios a Internet en 2019 fueron: celular inteligente (Smartphone) con 95.3\%; computadora portátil con $33.2 \%$, y computadora de escritorio con 28.9 por ciento.

\section{ANTECEDENTES Y EVOLUCIÓN DE LA ESTRUCTURA LEGAL DE LA TRANSPARENCIA Y EL DERECHO DE ACCESO A LA INFORMACIÓN PÚBLICA.}

\footnotetext{
6 Quintanilla Gabriela y Gil García José Ramón, Gobierno abierto y datos vinculados: conceptos, experiencias y lecciones con base en el caso de mexicano, en la Revista Reforma y Democracia. №.65. CLAD. Venezuela,2016, p.72
} 


\section{Participación de la sociedad civil en el derecho de acceso a la información pública}

Volumen 12, Número 22 ene-jun 2020

Morales Tostado \& Monterde Valenzuela

El derecho de acceso a la información pública, tiene su sustento en la Constitución Política de los Estados Unidos Mexicanos, donde se incorporó desde 1917. Sin embargo, fue algo olvidado y no se consideró una prioridad por los gobiernos, el hecho de proporcionar información a la sociedad sobre su desempeño. Fue hasta el año 2002 cuando se aprobó la ley de transparencia y en ella se establece la obligación de informar a la sociedad y con ello, se da inicio a una nueva relación entre el gobierno y la sociedad. Así mismo, en mayo de 2015 se publica en el Diario Oficial de la Federación la nueva Ley General de Transparencia y Acceso a la Información Pública LGTAIP.

En las agendas de la mayoria de los gobiernos, se establece por su importancia el derecho de acceso a la información y la participación ciudadana. En nuestro país, se han llevado a cabo cambios estructurales con el propósito de responder a las exigencias que se han planteado tanto en el contexto internacional como en el nacional, propiciando, la participación ciudadana en el legítimo uso del derecho a la información que abona a un cambio cultural que promueve que los ciudadanos se involucren de manera directa en la evaluación y seguimiento de la gestión pública.

El derecho de acceso a la información se considera un derecho humano fundamental consagrado en una serie de instrumentos internacionales de derechos humanos, López ${ }^{7}$ señala que: "Los derechos humanos son una de las primeras y más importantes expresiones, se plasmó en Francia en 1789 con la Declaración de los Derechos del Hombre y Ciudadano". De igual manera, son instrumentos importantes la Declaración Universal de los Derechos Humanos, el Pacto Internacional de Derechos Civiles y Políticos y la Convención Americana de Derechos Humanos. En

\footnotetext{
${ }^{7}$ López Ayllón Sergio El Acceso a la información como derecho fundamental: la reforma al artículo 6 de la Constitución mexicana. Cuaderno número 17. IFAl. México, 2009,p.11
} 
1946, la Asamblea General de Naciones Unidas, afirmó en su resolución 59. La libertad de información es un derecho humano fundamental y la piedra angular de todas las libertades a las que están consagradas las Naciones Unidas. Es en esa resolución, donde se desprende que el derecho de acceso a la información debe defenderse como un fin en sí mismo, en su carácter de derecho fundamental, y como un medio, en su dimensión de derecho facultativo para la exigencia de otros derechos.

También, la Corte Interamericana de Derechos Humanos dictaminó que la información pertenece a las personas, la información no es propiedad del Estado y el acceso a ella no se debe a la gracia o favor del gobierno. Es importante señalar que las instituciones del Estado tienen disposiciones que les obliga a brindar información sobre su desempeño y al mismo tiempo, le corresponde la protección de los derechos de las personas y de sus datos personales. La información de interés público, se refiere a la que surge o se encuentra en posesión de las autoridades en función de las atribuciones del Estado, misma que será pública y podrá ser solicitada por los ciudadanos.

El derecho a la información pública, ha adquirido notoria importancia en el mundo de las ideas políticas, sociales y jurídicas del pensamiento contemporáneo; al grado de que se le considera como uno de los rasgos más distintivos de los Estados constitucionales modernos, esto en virtud, de que el acceso a la información forma parte de una corriente universal, que va mucho más allá de una administración y se exige que se observe como un auténtico derecho y no sea ignorado, evadido o pospuesto.

Con todos esos cambios en el entorno internacional y los que a su vez se han realizado a las leyes mexicanas, se origina una nueva perspectiva ciudadana, la cual se nutre con la información que genera el gobierno en su desempeño y también le permite conocer los motivos en los que se basan para tomar determinadas decisiones en cualquier área incluyendo el manejo de los recursos económicos que la ciudadanía le proporciona al gobierno en forma de contribuciones. 


\section{Participación de la sociedad civil en el derecho de acceso a la información pública}

Volumen 12, Número 22 ene-jun 2020

Morales Tostado \&

Monterde Valenzuela

El fundamento legal para hacer uso del derecho de acceso a la información pública en la República Mexicana, lo constituye el artículo 6 constitucional que dentro de las garantías individuales o derechos humanos, consagra al derecho de acceso a la información en el ámbito federal, estatal y municipal. Dicho artículo se ha venido adecuado a las necesidades y demandas de la sociedad con el objetivo de brindar certidumbre jurídica al solicitar por parte de los ciudadanos información pública. Enseguida se presenta en forma resumida las modificaciones que ha sufrido.

Cuadro 1: Reformas al artículo 6 constitucional

\begin{tabular}{|c|c|}
\hline $\begin{array}{c}\text { Modificación } \\
\text { de } 1917\end{array}$ & $\begin{array}{l}\text { La manifestación de las ideas no será objeto de ninguna inquisición judicial o } \\
\text { administrativa, sino en el caso de que ataque a la moral, los derechos de terceros, } \\
\text { provoque algún delito o perturbe el orden público }\end{array}$ \\
\hline $\begin{array}{l}\text { Modificación } \\
\text { del en } 1977\end{array}$ & $\begin{array}{l}\text { La manifestación de las ideas no será objeto de ninguna inquisición judicial o } \\
\text { administrativa, sino en el caso de que ataque a la moral, los derechos de terceros, } \\
\text { provoque algún delito, o perturbe el orden público; el derecho a la información será } \\
\text { garantizado por el estado. }\end{array}$ \\
\hline $\begin{array}{l}\text { Modificación } \\
\text { del } 20 \text { de } \\
\text { Julio de } \\
2007\end{array}$ & $\begin{array}{l}\text { La manifestación de las ideas no será objeto de ninguna inquisición judicial o } \\
\text { administrativa, sino en el caso de que ataque a la moral, los derechos de terceros, } \\
\text { provoque algún delito, o perturbe el orden público; el derecho a la información será } \\
\text { garantizado por el estado. Se adicionan siete fracciones }\end{array}$ \\
\hline $\begin{array}{l}\text { Modificación } \\
\text { del } 13 \text { de } \\
\text { Noviembre } \\
2007\end{array}$ & $\begin{array}{l}\text { La manifestación de las ideas no será objeto de ninguna inquisición judicial o } \\
\text { administrativa, sino en el caso de que ataque a la moral, los derechos de terceros, } \\
\text { provoque algún delito, o perturbe el orden público; el derecho de réplica será ejercido } \\
\text { en los términos dispuestos por la ley, el derecho a la información será garantizado } \\
\text { por el estado. }\end{array}$ \\
\hline $\begin{array}{l}\text { Modificación } \\
\text { del } 11 \text { de } \\
\text { junio } 2013\end{array}$ & $\begin{array}{l}\text { La manifestación de las ideas no será objeto de ninguna inquisición judicial o } \\
\text { administrativa, sino en el caso de que ataque a la moral, la vida privada o los derechos } \\
\text { de terceros, provoque algún delito, o perturbe el orden público; el derecho de réplica } \\
\text { será ejercido en los términos dispuestos por la ley, el derecho a la información será } \\
\text { garantizado por el estado. } \\
\text { Toda persona tiene derecho al libre acceso a la información plural y oportuna, así } \\
\text { como a buscar, recibir y difundir información e ideas de toda índole por cualquier } \\
\text { medio de expresión.Se incorpora los apartados A y } \mathrm{B} \text {, donde se establece que el } \\
\text { Estado garantizará el derecho de acceso a las tecnologías de la información y } \\
\text { comunicación, así como a los servicios de radiodifusión y telecomunicaciones, incluido } \\
\text { el de banda ancha e internet. }\end{array}$ \\
\hline $\begin{array}{l}\text { Modificación } \\
\text { del } 07 \text { de } \\
\text { febrero } 2014 \\
\text { Se reforma } \\
\text { la fracción I, } \\
\text { IV, V de la } \\
\text { letra A. }\end{array}$ & $\begin{array}{l}\text { Lo relevante la adición de la fracción VIII que fundamenta el contar con un organismo } \\
\text { autónomo, especializado, imparcial, colegiado, con personalidad jurídica y patrimonio } \\
\text { propio, con plena autonomía técnica, de gestión, con capacidad para decidir sobre el } \\
\text { ejercicio de su presupuesto y determinar su organización interna, responsable de } \\
\text { garantizar el cumplimiento del derecho de acceso a la información pública y a la } \\
\text { protección de datos personales en posesión de los sujetos obligados en los términos } \\
\text { que se establezca en la Ley. }\end{array}$ \\
\hline $\begin{array}{l}\text { Modificación } \\
\text { del } 07 \text { de } \\
\text { febrero } 2014\end{array}$ & $\begin{array}{l}\text { Se establecerán mecanismos de acceso a la información y procedimientos de revisión } \\
\text { expeditos que se sustanciarán ante los organismos autónomos especializados e } \\
\text { imparciales que establece esta Constitución. Los sujetos obligados deberán preservar } \\
\text { sus documentos en archivos administrativos actualizados y publicarán, a través de los } \\
\text { medios electrónicos disponibles, la información completa y actualizada sobre el }\end{array}$ \\
\hline
\end{tabular}




\begin{tabular}{|c|l|}
\hline & $\begin{array}{l}\text { ejercicio de los recursos públicos y los indicadores que permitan rendir cuenta del } \\
\text { cumplimiento de sus objetivos y de los resultados obtenidos }\end{array}$ \\
\hline $\begin{array}{c}\text { Modificación } \\
\text { del } 29 \text { de } \\
\text { enero de }\end{array}$ & $\begin{array}{l}\text { Se establece en el apartado A, que la Federación, Entidades Federativas se regirán } \\
\text { por los siguientes principios y bases:Otorga competencia al organismo garante para } \\
2016\end{array}$ \\
$\begin{array}{l}\text { conocer los asuntos relacionados con el acceso a la información y la protección de } \\
\text { datos personales de cualquier autoridad, entidad, órgano u organismo que formen } \\
\text { parte de alguno de los Poderes Legislativo, Ejecutivo y Judicial, órganos autónomos, } \\
\text { partidos políticos, fideicomisos y fondos públicos, así como de cualquier persona física } \\
\text { o moral o sindicatos que reciba y ejerza recursos públicos. }\end{array}$ \\
\hline
\end{tabular}

Fuente: Elaboración propia, con datos de la Constitución vigente en cada uno de los años señalados.

Es importante señalar que las modificaciones que se han realizado desde 2013 a la fecha y que se organizan en dos apartados denominados $\mathrm{A}$ y $B$, en materia de radiodifusión y telecomunicación, donde se establece que el Estado brinda la garantía a la población de su integración a la sociedad de la información y el conocimiento, mediante una política de inclusión digital universal, considerando que las telecomunicaciones son servicios públicos de interés general y deben ser prestados en condiciones de competencia, calidad, pluralidad, cobertura universal, interconexión, convergencia, continuidad, acceso libre y sin injerencias arbitrarias. Como se puede apreciar es un proyecto ambicioso que compromete el Estado, en especial lo relacionado a que garantizará a la población su integración a la sociedad de la información y el conocimiento, mediante una política de inclusión digital universal con metas anuales y sexenales.

Todo esto, requiere el diseño de estrategias que tengan como objetivo dar cumplimiento a tan importante derecho y como el Estado mexicano otorga la garantía y está plasmado en la Constitución, no debe evadirse ni posponer.

Una vez que se analiza la información constitucional, vale la pena continuar con la revisión y análisis de la Ley principal: la Ley General de Transparencia y Acceso a la Información Pública (LGTAIP), publicada en el Diario oficial de la federación el 4 de mayo de 2015 y que tiene como antecedente la Ley Federal de Transparencia y Acceso a la Información Pública Gubernamental que inició vigencia en el año 2002. 


\section{Participación de la sociedad civil en el derecho de acceso a la información pública}

Volumen 12, Número 22 ene-jun 2020

Morales Tostado \& Monterde Valenzuela

Para entrar en materia, se define la Ley de acceso a la información, Ackerman y Sandoval ${ }^{8}$ la describen como "una ley que otorga a los ciudadanos el derecho a conseguir información bajo el resguardo del gobierno, sin la necesidad de demostrar interés legal".

Se considera que las leyes de transparencia forman parte de un proyecto diseñado para la formación de los ciudadanos, donde se busca que se incorporen los valores de responsabilidad, respeto, honestidad, tolerancia, entre otros, dicho proyecto debe darse desde los espacios formativos, tales como escuelas y universidades y organizaciones de la sociedad civil.

Al revisar las disposiciones de la nueva ley de transparencia es necesario señalar algunos artículos de la LGTAIP, con el objetivo de precisar en qué consiste el derecho humano de acceso a la información y para tal efecto se cita el artículo 4 de la LGTAIP:

Artículo 4. El derecho humano de acceso a la información comprende solicitar, investigar, difundir, buscar y recibir información.

Toda la información generada, obtenida, adquirida, transformada o en posesión de los sujetos obligados es pública y accesible a cualquier persona en los términos y condiciones que se establezcan en la presente Ley, en los tratados internacionales de los que el Estado mexicano sea parte, la Ley Federal, las leyes de las Entidades Federativas y la normatividad aplicable en sus respectivas competencias; sólo podrá ser clasificada excepcionalmente como reservada temporalmente por razones de interés público y seguridad nacional, en los términos dispuestos por esta Ley.

En esa misma tesitura, la Ley de Transparencia, en su artículo 8 establece los principios rectores de los organismos garantes y define: certeza,

\footnotetext{
${ }^{8}$ ACKERMAN M. John. SANDOVAL Irma. Leyes de Acceso a la Información en el Mundo. Cuadernos de Transparencia Número 7. IFAI. México, 2008, p. 11
} 
eficacia, imparcialidad, independencia, legalidad, máxima publicidad, objetividad, profesionalismo y transparencia. Por tanto, la identificación y descripción de los principios esta dado, solo falta que se cumplan y respeten en el desempeño de los servidores públicos que forman parte de los organismos garantes.

De igual manera, es necesario precisar quiénes son los sujetos obligados y al respecto el artículo 23 describe en detalle quienes tienen la obligación de cumplir con lo establecido en la LGTAIP:

Son sujetos obligados a transparentar y permitir el acceso a su información y proteger los datos personales que obren en su poder: cualquier autoridad, entidad, órgano y organismo de los Poderes Ejecutivo, Legislativo y Judicial, órganos autónomos, partidos políticos, fideicomisos y fondos públicos, así como cualquier persona física, moral o sindicato que reciba y ejerza recursos públicos o realice actos de autoridad en los ámbitos federal, de las Entidades Federativas y municipal.

El cumplimiento de las obligaciones de los sujetos obligados va más allá de las relacionadas a transparentar y dar a conocer la información que soliciten los ciudadanos, adicionalmente tienen una serie de obligaciones relacionadas a la organización de la estructura que se requiere para estar en condiciones de ofrecer a los ciudadanos todo lo que a derecho le corresponde, todas esas obligaciones las contiene el artículo 24 de la LGTAIP que se cita a continuación

Para el cumplimiento de los objetivos de esta Ley, los sujetos obligados deberán cumplir con las siguientes obligaciones, según corresponda, de acuerdo a su naturaleza:

I. Constituir el Comité de Transparencia, las Unidades de Transparencia y vigilar su correcto funcionamiento de acuerdo a su normatividad interna

II. Designar en las Unidades de Transparencia a los titulares que dependan directamente del titular del sujeto obligado y que preferentemente cuenten con experiencia en la materia. 


\section{Participación de la sociedad civil en el derecho de acceso a la información pública}

Volumen 12, Número 22 ene-jun 2020

Morales Tostado \& Monterde Valenzuela

III. Proporcionar capacitación continua y especializada al personal que forme parte de los Comités y Unidades de Transparencia

IV. Constituir y mantener actualizados sus sistemas de archivo y gestión documental, conforme a la normatividad aplicable

V. Promover la generación, documentación y publicación de la información en formatos abiertos y accesibles

VI. Proteger y resguardar la información clasificada como reservada o confidencial.

VII. Reportar a los Organismos garantes competentes sobre las acciones de implementación de la normatividad en la materia, en los términos que éstos determinen

VIII. Atender los requerimientos, observaciones, recomendaciones y criterios que, en materia de transparencia y acceso a la información, realicen los Organismos garantes y el Sistema Nacional

IX. Fomentar el uso de tecnologías de la información para garantizar la transparencia, el derecho de acceso a la información y la accesibilidad a éstos

X. Cumplir con las resoluciones emitidas por los Organismos garantes

XI. Publicar y mantener actualizada la información relativa a las obligaciones de transparencia

XII. Difundir proactivamente información de interés público

XIII. Dar atención a las recomendaciones de los Organismos garantes

XIV. Las demás que resulten de la normatividad aplicable.

Todos estos cambios a las legislaciones mexicanas encaminadas a dar sustento a la transparencia y acceso a la información pública se despliegan en el contexto de un compromiso internacional por contener la corrupción el cual fue expresado en la Convención de la ONU contra la Corrupción, cuyo texto se publicó en diciembre de 2003.

A partir de la entrada en vigor de la Ley de Transparencia, las entidades del gobierno federal y las entidades que reciben recursos púbicos, tienen la obligación de dar a conocer su desempeño. Todo ello, coadyuva a que los ciudadanos recuperen la confianza en el gobierno, al conocer la información sobre la gestión pública, incluyendo los presupuestos donde se identifique el origen y aplicación de los ingresos. 
En la LGTAIP, en el artículo 37 se señalan las características del organismo garante y dentro de ellas se puede mencionar que debe ser autónomo, especializado, independiente, imparcial y colegiado, con personalidad jurídica y patrimonio propio y establece también que deber de tener plena autonomía técnica, de gestión, capacidad para decidir sobre el ejercicio de su presupuesto.

Otro cambio importante que abona a la transparencia y al derecho de acceso a la información pública es la creación del Sistema Nacional de Transparencia, Acceso a la Información Pública y Protección de Datos Personales.

Todas estas disposiciones y modificaciones brindan certidumbre a los ciudadanos para solicitar información a los servidores públicos y si no atienden y entregan la información solicitada, pueden recurrir al organismo garante, Un dato importante es que los países con menor corrupción en el mundo, tienen una sólida ley de acceso a la información.

\section{PARTICIPACIÓN DE LA SOCIEDAD CIVIL}

La literatura sobre la participación de la sociedad civil, se puede analizar desde diferentes aspectos, iniciando por el hecho de que existen varias definiciones de sociedad civil, para nuestro propósito es suficiente decir que cubre todas las actividades que son independientes de los Estados y mercados, basadas en una actividad voluntaria sin ánimo de lucro. La sociedad civil está integrada por organizaciones no gubernamentales, organizaciones sin ánimo de lucro, comunitarias, de autoayuda, sindicatos, religiosas y cooperativas, voluntariado, movilización social, acción colectiva y demás manifestaciones de la sociedad civil.

La participación de la sociedad civil en el uso legítimo del derecho a la información ha propiciado avances significativos, en la mayoría de las discusiones sobre la política de transparencia y acceso a la información subrayan la importancia de que la sociedad civil vigile los procesos mediante los cuales se garantiza el derecho a la información. 


\section{Participación de la sociedad civil en el derecho de acceso a la información pública}

Volumen 12, Número 22 ene-jun 2020

Morales Tostado \& Monterde Valenzuela

Al respecto Luna 9 , señala que "la sociedad en México ha respondido de manera lenta asimilando y comprendiendo los usos, alcances y límites del derecho de acceso a la información", quizá esto va a cambiar cuando realmente se refleje el impacto en la gestión pública, con servidores comprometidos con la sociedad y con ello, puede revertir aunque sea un poco, la desconfianza hacia las instituciones públicas.

La temática sobre transparencia y acceso a la información pública, resulta interesante ya que los ciudadanos no tiene confianza en el gobierno, por los repetidos actos de corrupción que se dan a conocer en los medios de comunicación, también, por el tráfico de influencias y el proteccionismo a los integrantes de los grupos políticos, entre otros.

La transparencia y el derecho de acceso a la información, obliga a mantener un control sobre el quehacer de los servidores públicos y es elemento fundamental para estar en condiciones de cumplir con la obligación de rendición de cuentas.

Es interesante lo planteado por Vergara ${ }^{10}$ "En los últimos años nos encontramos con que diversos organismos internacionales como la OCDE y el Banco Mundial han comenzado a presionar a los gobiernos nacionales para transparentar su información y explicar sus decisiones". Esto por considerar que muchas de las crisis y decisiones gubernamentales equivocadas, se hubieran podido evitar si la sociedad tuviera el conocimiento de la información pública.

La transparencia como cultura política y ciudadana, encuentra sus principales razones en el sistema político mexicano. Esto en virtud, de que enfrenta una crisis de credibilidad y de representatividad, lo cual se originó

\footnotetext{
${ }^{9}$ Luna Pla Issa. Movimiento social del derecho de acceso a la información en México. México. Instituto de investigaciones jurídicas (IIJ). UNAM. México, 2009, p. 163 10 Vergara, op. cit., 28
} 
debido principalmente a las experiencias de corrupción y clientelismo político que ha vivido el país a lo largo de su historia.

De tal forma, que al no tener los ciudadanos confianza en las instituciones públicas, se refleja en el desinterés de inversión privada para reactivar la economía nacional y en la evasión de impuestos aduciendo que no se utilizan para el bien común, entre otros. Por ello, la transparencia se presenta como estrategia para construir la confianza de los ciudadanos.

La capacidad que tiene la sociedad de evaluar el desempeño de sus gobernantes y de exigirles cuentas claras sobre su quehacer, depende que se disponga de información fidedigna, oportuna y comprensible sobre los objetivos, metas y resultados gubernamentales.

En nuestro país, el reto de ser transparente no debe ni puede aplazarse ya que en los últimos años es una exigencia que hacen diversos organismos internacionales, en virtud de que se considera que muchas de las crisis que se han presentado en México, son producto de decisiones gubernamentales equivocadas, las cuales, se hubieran podido evitar si la sociedad tuviera el conocimiento de la información pública.

La transparencia y el acceso a la información son pilares indispensables de cualquier sistema moderno de administración y es esencial para la rendición de cuentas a la sociedad. Por ello Vergara ${ }^{11}$ señala que:

La transparencia en el contexto gubernamental tiene consecuencias organizacionales importantes: Disminuye las asimetrías de información $y$, por tanto, permite una mejor supervisión interna de políticos y funcionarios. De esta manera previene actos de corrupción y sirve de incentivo a los funcionarios públicos para mejorar su desempeño.

Todo esto, parece confirmar que las instituciones públicas al permitir la transparencia y el acceso a la información, están fijando las bases para la rendición de cuentas. Siendo una prioridad que la ciudadanía conozca cómo

\footnotetext{
11 Vergara, op. Cit., 33
} 


\section{Participación de la sociedad civil en el derecho de acceso a la información pública}

Volumen 12, Número 22 ene-jun 2020

Morales Tostado \& Monterde Valenzuela

se utilizan los recursos por parte del gobierno y con ello evaluar a los servidores públicos, al mismo tiempo, le brinda la posibilidad de incidir en las decisiones de políticas públicas que en última instancia, se diseñan para su beneficio.

En ese sentido, al saber los servidores públicos que pueden ser descubiertos por alguna solicitud de información y se ponga de manifiesto su conducta discrecional o ilegal, sin duda cuidaran su desempeño, además estas conductas son motivo de sanciones estipuladas en la propia Ley de Transparencia y en la Ley de Responsabilidades de los Servidores Públicos.

Se considera, que solamente con la participación de la sociedad, se puede contribuir a la formación de los servidores públicos que deben estar comprometidos a respetar las leyes y con la cultura de honestidad y fortalecimiento de una ética pública a favor de los ciudadanos, la corrupción en el sector público sigue siendo uno de los temas más importantes y urgentes en la agenda nacional.

En ese tenor, es importante compartir lo planteado por Arenilla Sáez

La finalidad es lograr ciudadanos que entiendan mejor los asuntos públicos y sean más exigentes con sus representantes y dirigentes políticos y dirigentes políticos más responsables. En definitiva, el ejercicio de la transparencia supone la redistribución del poder actual de los dirigentes políticos entre los ciudadanos y un mayor empoderamiento de estos. ${ }^{12}$

En esa tesitura, la transparencia y el derecho de acceso a la información, representa una de las conquistas ciudadanas más importantes del México contemporáneo.

De igual forma, la Ley de Transparencia, propicia que los servidores públicos realicen su gestión con un enfoque honesto, transparente y con

\footnotetext{
12 Vide:Arenilla Sáez Manuel Transparencia, Accesibilidad y Rendición de Cuentas, en Administración 2032. Teclas para transformar la Administración Pública Española. Grupo de Investigación en Administración Pública 2032. GIAP 2032, INAP, España,2014,p.
} 
interés por informar y rendir cuentas a la sociedad. Por lo tanto, al ejercer los ciudadanos el derecho de acceso a la información pueden conocer cualquier información del gobierno que puede incluir el presupuesto asignado a las Instituciones que forman parte del gobierno federal, estatal y municipal y los informes de su ejecución, entre otra información financiera.

Al concientizar a los ciudadanos sobre lo importante de su participación y al hacer efectivo el derecho de acceso a la información, se podrá influenciar para que la toma de decisiones, así como, la formulación, instrumentación, monitoreo y evaluación de políticas públicas sobre la acción gubernamental se lleve a cabo apegadas a las leyes.

Aunado a ellos Merino comparte lo siguiente:

El conocimiento de los asuntos públicos que favorece la transparencia ha hecho posible que, cada vez más, los ciudadanos organizaciones sociales, empresariales, académicas y medios de comunicación monitoreen las acciones y decisiones de los gobiernos y esa observación permanente desincentiva los intercambios corruptos. ${ }^{13}$

Sin duda, en México están emergiendo nuevas formas de participación ciudadana, los ciudadanos exigen a sus gobiernos que deben ser eficientes, flexibles, responsables, orientados en base a resultados y deben ser transparentes, abiertos al escrutinio público y garantes del derecho que cualquier ciudadano tiene a acceder a la información en manos de las instituciones y de los servidores públicos y demanda la oportunidad de participación en la elaboración de las políticas públicas.

La relación entre el estado y sociedad civil es compleja y problemática, tradicionalmente el Estado apoya las actividades de la sociedad civil como una cuestión de principios, simplemente porque son manifestaciones del derecho de asociación de los ciudadanos. Hoy, este principio se enfrenta a la creciente presión por el énfasis puesto en la gestión, la vigilancia de los resultados y la participación de las organizaciones de la sociedad civil.

\footnotetext{
${ }^{13}$ Merino Mauricio, (2018). Opacidad y corrupción: las huellas de la captura. Cuadernos de Transparencia número 26. INA,2018,p.18
} 


\section{Participación de la sociedad civil en el derecho de acceso a la información pública}

Volumen 12, Número 22 ene-jun 2020

Morales Tostado \& Monterde Valenzuela

Es importante recordar que en el deber ser, los ciudadanos dirigen el Estado en lugar de lo contrario. En este proceso, se requieren debates abiertos y libres con la participación de integrantes del gobierno y de la sociedad civil. En especial en un país en el que la desigualdad es uno de los principales problemas que enfrenta la población, las organizaciones civiles adquieren un compromiso especial con el desarrollo económico, social, cultural y el impulso de una ciudadanía plena y responsable.

En una sociedad plural, como la mexicana, la convivencia diaria tiene que fundamentarse en virtudes cívicas como la tolerancia, el respeto a las leyes y a los derechos de terceros. En el ejercicio ciudadano del derecho de acceso a la información, se han constituido organizaciones civiles que promueben la transparencia, el derecho de acceso a la información. Una de estas organizaciones de la sociedad civil, se le conoce como: El Colectivo por la Transparencia, surgió a finales del año 2002 como un espacio de reflexión y acción, conformado por seis organizaciones de la sociedad civil. Para mayo de 2018 se han sumado otras organizaciones a este esfuerzo, quedando integrado por las siguientes instituciones:

Cuadro 2: Colectivo por la transparencia

\begin{tabular}{|l|l|}
\hline \multicolumn{1}{|c|}{ Organización } & \multicolumn{1}{|c|}{ Dirección electrónica } \\
\hline 1. Alianza Cívica & www.alianzacivica.org.mx \\
\hline $\begin{array}{l}\text { 2. } \\
\text { Información Accesible y Rendición de Cuentas } \\
\text { (IARAC) }\end{array}$ & www.iaracredes.wix.com \\
\hline 3. Visión Legislativa & www.visionlegislativa.com \\
\hline 4. Centro Mexicano de Derecho Ambiental & www.cemda.org.mx \\
\hline $\begin{array}{l}\text { 5. } \\
\text { Colectivo Ciudadanos por Municipios }\end{array}$ & Transparentes (CIMTRA)
\end{tabular}




\begin{tabular}{|l|l|}
\hline $\begin{array}{l}\text { 14. Centro Nacional de Comunicación Social } \\
\text { (CENCOS) }\end{array}$ & www.cencos.org \\
\hline 15. Equis Justicia para las Mujeres & www.equis.org.mx \\
\hline 16. Gente Diversa de Baja California & www.gentediversa.org.mx \\
\hline
\end{tabular}

Fuente: Elaboración propia con datos de la página web del Colectivo por la Transparencia localizada en: http://colectivoporlatransparencia.org/quienes

En México a partir del año 2000 se han establecido condiciones que fomentan las organizaciones civiles, se puede mencionar la creación de un marco normativo para identificar y regular la actividad de las organizaciones civiles, el cual constituye las bases para la institucionalización de la relación con las organizaciones civiles. Adicionalmente se estableció el Registro Nacional de Instituciones y Organizaciones Políticas Sociales y Civiles, para identificar aquellas con causas similares, a fin de propiciar su trabajo conjunto.

Por ello, es necesario que realmente se lleve a la práctica acciones tendientes a promover la creación de organizaciones de participación ciudadana como mecanismos fundamentales para el diseño de las políticas públicas, la transparencia y la rendición de cuentas.

Esta estrategia busca impulsar que los ciudadanos participen de forma activa en el monitoreo, el seguimiento y la evaluación de la gestión pública, con la finalidad de que estas acciones se traduzcan en medidas correctivas dentro de la función pública.Para implementar la estrategia se requiere construir alianzas con la sociedad civil y el establecimiento de foros permanentes de consulta, evaluación y seguimiento sobre la gestión gubernamental donde participe la sociedad. Por otra parte, es necesario desarrollar e implementar estrategias que permitan la participación ciudadana en los procesos de toma de decisión para mejorar la gestión pública.

En ese tenor, Egaña Baraona señala lo siguiente:

Esta mirada desde la complejidad del entorno obliga también a comprender los actores que juegan un rol relevante en dichas instituciones, los grupos sociales o de ciudadanos con quienes deberán interactuar, los sistemas de participación que deberán tener, las normas éticas y de probidad a las cuales estarán sometidas, la transparencia a la cual estarán obligadas, el sistema político que tendrá influencia en 


\section{Participación de la sociedad civil en el derecho de acceso a la información pública}

Volumen 12, Número 22 ene-jun 2020

Morales Tostado \& Monterde Valenzuela

cada institución, junto con el régimen de vinculación con autoridades superiores de gobierno, tanto a niveles centrales, regionales o locales.

Como se puede apreciar el entorno es complejo y solo interactuando los servidores públicos en representación de las instituciones y los grupos de ciudadanos, se avanzarán a un mejor desempeño del gobierno. ${ }^{14}$

Otro aspecto a considerar, es el relacionado a la utilización de la tecnología de información y comunicación, mecanismo necesario para ejercer el derecho de acceso a la información, en México existen todavia ciudadanos que no usan internet, por tanto, no gozan de las facilidades para conocer la información pública, a pesar de que en el artículo 6 constitucional se establece que a partir de junio de 2013 el Estado garantizará a los ciudadanos la inclusión digital universal, lo que a la fecha no se ha logrado, ya que la Encuesta Nacional sobre Disponibilidad y Uso de Tecnologías de la Información en los Hogares, que se dio a conocer en febrero de 2020, reporta que en México hay 80.6 millones de usuarios de Internet, que representan el $70.1 \%$ de la población de seis años o más y estima que son 20.1 millones el número de hogares que disponen de Internet, ya sea mediante una conexión fija o móvil y eso nos lleva a preguntar: ¿ y el resto de los mexicanos?

El gobierno mexicano enfrenta muchos retos por la problématica que está presente en la sociedad, como el aumento progresivo de las personas que viven en pobreza, la inseguridad en todo su territorio, los procesos electorales costosos, los escándalos de corrupción, entre otros, cada uno de ellos es quizá de mayor prioridad que el brindar acceso a la información pública.

\footnotetext{
${ }^{14}$ Egaña Baraona Rodrigo,Fortalecimiento Institucional: Una mirada desde la experiencia, en 20 años de Congresos CLAD, Aportes a la Reforma del Estado y la Administración Pública en Iberoamérica. CLAD. Venezuela,2015,p.67
} 
Sin embargo, la transparencia y acceso a la información permea en cada uno de ellos, si hay información real, que no haya sido manipulada con intereses políticos, se conocerá a ciencia cierta el número de mexicanos que viven en pobreza, los casos de inseguridad e impunidad que se dan en el país, el monto real de los recursos públicos que se destinan a sufragar las compañas políticas, que apoyos gubernamentales reciben y que requisitos solicita el gobierno para entregar dichos apoyos.

Al igual que la transparencia de la información gubernamental, el derecho de acceso a la información garantizado en la Constitución, constituye un instrumento que propicia la participación de los ciudadanos.

El empoderamiento de los ciudadanos, nos lleva a realizar el análisis de la participación social como un elemento relevante hacia un gobierno abierto, que goza de la confianza de sus ciudadanos. Es por ello, que se indagó el número de solicitudes que recibe el órgano garante y se puede observar que año con año se incrementa el número de solicitudes de información pública. En la siguiente gráfica se puede conocer el número de solicitudes de información del ámbito federal.

Gráfica 1: Solicitudes de información pública de 2003 a 2019.

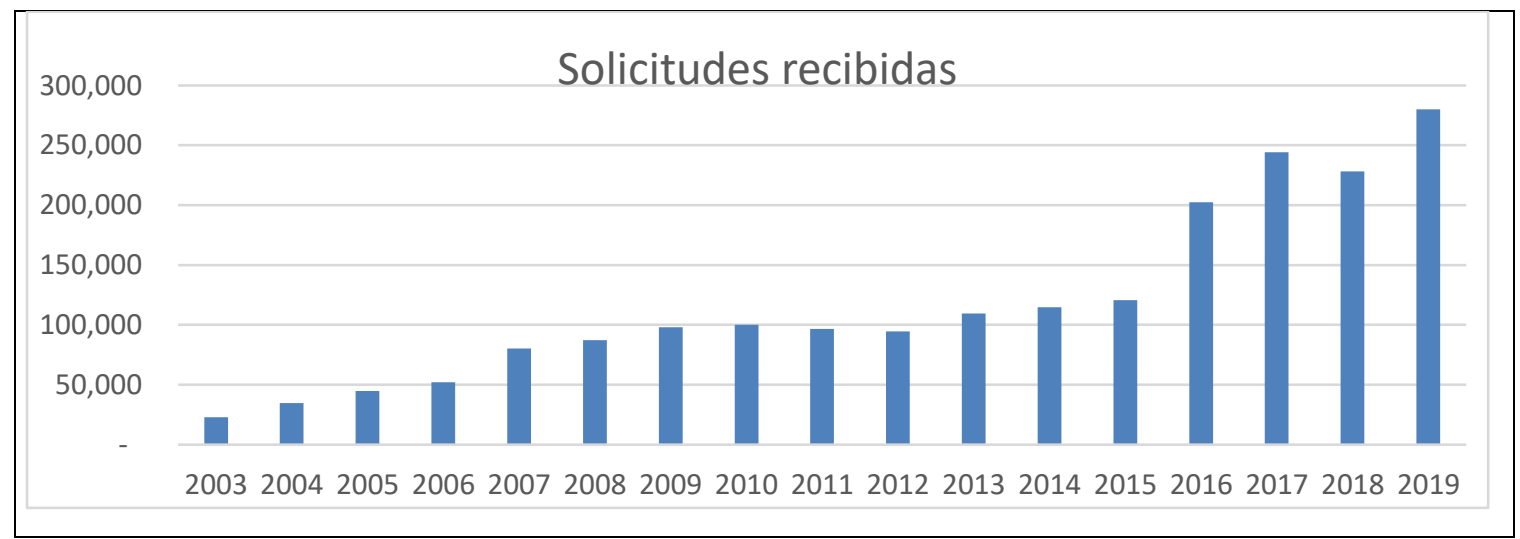

Fuente: Información recuperada del Informe del INAI 2020 localizado en:

https://micrositios.inai.org.mx/informesinai/?page_id=15 


\section{Participación de la sociedad civil en el derecho de acceso a la información pública}

Volumen 12, Número 22 ene-jun 2020

Morales Tostado \& Monterde Valenzuela

En la gráfica anterior, se puede observar que año tras año se van incrementando las solicitudes de información pública que realizan los ciudadanos a las instituciones gubernamentales.

Aunque en 2011 y 2012 disminuyó el número. El incremento mayor se presentó de 2015 a 2017 donde casi se duplica el número de solicitudes.

\section{CONCLUSIONES}

La transparencia y el derecho de acceso a la información, representan una de las conquistas ciudadanas más importantes del México contemporáneo. Con la entrada en vigor de la LGTAIP, obliga a las instituciones del gobierno a proporcionar a los ciudadanos la información que les interese sobre la gestión gubernamental, el uso de los recursos públicos y la toma de decisiones y cualquier información que los ciudadanos soliciten. Con ello, México se encamina hacia un gobierno abierto, flexible y transparente, que promueve la cultura ciudadana.

Las modificaciones a la Constitución Política de los Estados Unidos Mexicanos en materia de transparencia, han contribuido a tener un panorama con políticas de apertura desde dos angulos; el primero; la política que obliga a proporcionar la información necesaria para conocer el desempeño del gobierno y la segunda; para promover la participación de la sociedad civil.

Sin duda, se transita por nuevos caminos y aunque esos nuevos caminos son resultado de exigencias internacionales, es benéfico el hecho de establecer de manera detallada las obligaciones de transparencia y acceso a la información y brinda mayor certidumbre a los ciudadanos, de cumplirse a cabalidad dichas obligaciones, se coadyuva a que los ciudadanos recuperen la confianza en el gobierno, al conocer la información sobre la gestión pública, incluyendo los presupuestos donde se identifique el origen y aplicación de los ingresos.

La sociedad mexicana, ha respondido de manera lenta, todavía no se tiene claro los beneficios de utilizar el derecho de acceso a la información, quizá esto va a cambiar con el paso de los años, cuando realmente se refleje el impacto en la gestión pública, con servidores públicos comprometidos con la sociedad a la cual se deben.

El gobierno mexicano enfrenta una crisis de credibilidad y de representatividad, lo cual se originó debido principalmente a las experiencias 
de corrupción y clientelismo político que ha vivido el país a lo largo de su historia. Por tanto, la transparencia como cultura política y ciudadana puede constituir un detonante para mejorar la credibilidad y construir lazos entre los ciudadanos.

Se considera que con la transparencia y el acceso a la información, se pondrá un freno a la comisión de actos deshonestos o decisiones discrecionales de parte de los servidores públicos, para con ello contribuir a la credibilidad. Ya que a medida que los servidores públicos saben que sus decisiones o acciones podrán ser conocidas por los ciudadanos en cualquier momento mediante una solicitud de información, cuidarán cometer irregularidades.

Es importante considerar a la transparencia como un elemento primordial para la reforma del Estado, esto en virtud de que contribuye al establecimiento de un nuevo tipo de gobierno. En resumidas cuentas, la transparencia es una medida que puede traer beneficios y que vale la pena asumir porque exige que el Estado escuche a la sociedad.

Para construir un mejor país, es necesario llevar a la práctica las acciones que contempla el programa nacional de rendición de cuentas, transparencia y combate a la corrupción. Conscientes de que cada mexicano se debe convertir en agente de cambio y entre todos difundir el derecho que tienen los ciudadanos a la información pública gubernamental de manera oportuna, suficiente y garantizada, así como la participación de la sociedad en el análisis y evaluación en el desempeño del gobierno.

En relación al marco legal de la transparencia y el derecho de acceso a la información se considera inacabado, por el hecho de requerir constantes ajustes para dar respuesta a un tejido social cambiante, por lo que es necesario la modificación de leyes secundarias que fortalezcan y apoyen el cumplimiento de tan importante derecho.

La transparencia y el acceso a la información es un tema político de moda, por ello en el discurso político se puede interpretar que todo está bien, que hay grandes avances. Sin embargo, es necesario investigar lo que realmente sucede en la realidad. Por tanto, es menester seguir con las investigaciones y contribuir a mejorar tanto la estructura jurídica como la administrativa y transitar a mejores condiciones de transparencia y acceso a la información pública.

Lo más importante para obtener resultados satisfactorios en la transparencia y el derecho de acceso a la información pública; es la voluntad política de los servidores públicos y que tanto el poder ejecutivo como el 


\section{Participación de la sociedad civil en el derecho de acceso a la información pública}

Volumen 12, Número 22 ene-jun 2020

Morales Tostado \&

Monterde Valenzuela

legislativo realicen acciones que coadyuven a mejorar en el cumplimiento de las obligaciones de transparencia y de acceso a la información.

\section{REFERENCIAS BIBLIOGRÁFICAS}

ACKERMAN M. John. SANDOVAL Irma. Leyes de Acceso a la Información en el Mundo. Cuadernos de Transparencia Número 7. IFAl. México, 2008,

ACKERMAN M. John,“El Caso de las Boletas Electorales”, en Más Allá del Acceso a la Información. Transparencia, rendición de cuentas y estado de Derecho. Siglo XXI Editores. México,2008

ARENILLA SÁEZ Manuel Transparencia, Accesibilidad y Rendición de Cuentas, en Administración 2032. Teclas para transformar la Administración Pública Española. Grupo de Investigación en Administración Pública 2032. GIAP 2032, INAP, España,2014

EGAÑA BARAONA Rodrigo,Fortalecimiento Institucional: Una mirada desde la experiencia, en 20 años de Congresos CLAD, Aportes a la Reforma del Estado y la Administración Pública en Iberoamérica. CLAD. Venezuela,2015

LÓPEZ AYLLÓN Sergio El Acceso a la información como derecho fundamental: la reforma al artículo 6 de la Constitución mexicana. Cuaderno número 17. IFAI. México, 2009

LUNA PLA Issa. Movimiento social del derecho de acceso a la información en México. México. Instituto de investigaciones jurídicas (IIJ). UNAM. México, 2009

MERINO Mauricio,La transparencia como política pública, en Ackerman (Coord). Más allá del acceso a la información. Transparencia, rendición de cuentas y Estado de Derecho. Siglo XXI. México,2008

MERINO Mauricio, (2018). Opacidad y corrupción: las huellas de la captura. Cuadernos de Transparencia número 26. INA,2018,

QUINTANILLA Gabriela y Gil García José Ramón, Gobierno abierto y datos vinculados: conceptos, experiencias y lecciones con base en el caso de mexicano, en la Revista Reforma y Democracia. №. 65. CLAD. Venezuela,2016

VERGARA Rodolfo, La Transparencia como problema. Serie de Cuadernos de transparencia número 5. México, 5ta. ed., IFAl. México,2008

WEBGRAFIA

Colectivo por la Transparencia localizada en: http://colectivoporlatransparencia.org/quienes Comunicado de INEGI 103/20.

https://www.inegi.org.mx/contenidos/saladeprensa/boletines/2020/OtrTemEcon/ENDUTIH_2

019.pdf

Convención de la ONU contra la Corrupción 2003

https://www.unodc.org/pdf/corruption/publications_unodc_convention-s.pdf

Informe del INAI 2020 localizado en:

https://micrositios.inai.org.mx/informesinai/?page_id=15

Recibido 14 de Junio de 2020

Aceptado 30 de Junio de 2020 